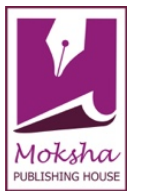

Research Article

www.ijrap.net

\title{
CARBOXYMETHYLATION (CM) OF NATURAL FIBRES: INVESTIGATING THE MOISTURE ABSORBENCY AND EVALUATING ANTIMICROBIAL PROPERTY OF HERBAL FINISHED CM-FIBRES Shabrin Farhana $\mathrm{G}^{* 1}$, Palaniswamy NK ${ }^{2}$ \\ ${ }^{1}$ Sr.Faculty, FDDI, Ministry of Commerce and Industry, Govt of India, Kancheepuram, Tamil Nadu, India \\ ${ }^{2}$ Professor, Department of Textile and Engineering, College of Engineering and Technology, University of Aksum, Ethiopia
}

Received on: 14/05/18 Accepted on: 05/06/18

*Corresponding author
E-mail: shabsfarhana@yahoo.com

DOI: $10.7897 / 2277-4343.09396$

\begin{abstract}
Carboxymethylation is the method of process used to increase the absorbency properties and to increase the water retention capacity of cotton fibres. Considering the significance of this process, in the present study, cotton was carboxymethylated using a standard protocol under controlled conditions. Scanning electron microscopy, vertical wicking and Fourier Transform Infra Red spectroscopic (FTIR) methods are used to ensure the increase in moisture absorbency and change in the functional groups of the fibre respectively. SEM analysis of CM cotton fibres were found swollen with few protruding microfibrils indicating that the fibre was modified with carboxyl ions. FTIR spectra of CM cotton fibre showed significant functional groups specifically for CM fibre samples alone. A broad band at $3417.30 \mathrm{~cm}^{-1} 1714.25 \mathrm{~cm}^{-1}$ and $1633.87 \mathrm{~cm}^{-1}$ attributed to carboxylic stretching of the $-\mathrm{OH}$ group, $\mathrm{C}=\mathrm{O}$ (carboxylic acid group) carboxylic stretching vibrations and symmetric stretching of carboxylate anion respectively. To reduce the epidermis-associated bacterial and candidal infections, herbal extracts (Gliricidia sepium, Hemigraphis colorata, Ichnocarpus frutescens and Caesalpinia bonduc) were finished on to CM cotton fibres. Test samples showed significant antibacterial inhibitory zones ranging from $24 \mathrm{~mm}$ to $33 \mathrm{~mm}$ against Escherichia coli and Staphylococcus aureus. Vertical wicking analysis showed greater absorbency and dye uptake for the carboxymethylated fibres than the normal fibres. The present research thus illustrated the significance of carboxymethylation process for the development of skin-friendly and eco-friendly products like baby diapers and sanitary napkins based on the results obtained from SEM, FTIR, wicking and antibacterial activity tests.
\end{abstract}

Key words: Carboxymethylation, Moisture absorbency, Water retention, Antimicrobial activity, FTIR.

\section{INTRODUCTION}

Direct contact of fabric with body causes the growth of microorganisms. Sanitary napkins are such type of products which are highly prone to microbial infestation; leading to cause skin infections in immuno-compromised and normal people ${ }^{1}$. Many bacterial and fungal species are causes sanitary napkinassociated infections. Hence, there is a strong need for a hygienic product for menstrual protection worldwide. To prevent infections on sanitary napkins, the fabrics should posses antimicrobial activity. In the women sanitary napkin market, the antimicrobial sanitary napkin may found its own place due to its infection disease preventive properties ${ }^{2}$. Clothing and textile are a very suitable media for the growth of the microorganisms ${ }^{3}$. They can act as the carriers for some microorganisms such as pathogenic bacteria, odour generating bacteria and mold or fungi. Natural finishes of herbal extracts on fabrics have many advantages such as non-toxic, non-irritant, biodegradable, cost effective and easy availability ${ }^{4}$. Finish of herbal extracts having antibacterial activity on fabrics, helps in reducing the growth of microbes. Thus the antimicrobial activity of fabrics can be obtained by finishing of herbal extracts on fibres. The bio active compounds present in herbal extracts are responsible for the antimicrobial activity. Based on the significances of herbal finish on fibres and fabrics, To reduce the epidermis-associated bacterial and/or candidal infections, four different types of herbal extracts (Gliricidia sepium, Hemigraphis colorata, Ichnocarpus frutescens and Caesalpinia bonduc) were finished on to the fibres to reduce the sanitary napkin (epidermis) associated bacterial and/or candidal infections, prior to the product development.
Carboxymethylation was carried out in the cotton fibre to form alkali cellulose. It is the method used to increase the absorbency properties and to increase the water retention capacity of any fibre/fabric materials. The alkali cellulose is modified to crystalline structure of cellulose and increases the accessibility of fibres to chemicals by swelling 5 . Carboxymethyl cellulose $(\mathrm{CMC})$ is the major cellulose ether. By activating the non-crystalline regions of cellulose, selective regions of alkylating reagents can attack the cellulose. This is termed the concept of reactive structure fractions and is used widely for the production of $\mathrm{CMC}^{6}$. The significance of Carboxymethylation process paved way to frame the following objectives in the present study.

The objective of the research is to carboxymethylate the cotton fibres for achieving enhanced liquid absorbency and water retention capacity. The testing parameters to meet these objective was carried out to investigate the possibility of developing sanitary napkins and baby diapers with more wicking properties; and to retard the sanitary napkin-associated infection causing organisms by finishing with the herbal extracts.

\section{MATERIALS AND METHODS}

\section{Procurement of cotton fibre and herbs}

The absorbent cotton fibre (Shanti Surgicals Pvt Ltd) was commercially procured from a surgical shop at Coimbatore, India. Herbal powders of Gliricidia sepium, Hemigraphis colorata, Ichnocarpus frutescens and Caesalpinia bonduc were procured from an organic store at Coimbatore, India. All chemicals (Nice, Loba, Merck), and Media (Hi Media, TM 
Media) was purchased commercially from chemical suppliers, Coimbatore. The entire research work was done during the period of December 2017 to March 2018.

\section{Carboxymethylation of cotton fibres ${ }^{5}$}

Carboxymethylated (CM) cotton fibre was prepared using a standard exhaustion method. Alkali cellulose was prepared by impregnating the fabric in 5\% sodium hydroxide solution in $95 / 5$ ethanol/water for 15 minutes at room temperature, then immersed to a wet pick-up of $100 \%$ and air dried. The fibre was lightly rolled and introduced into a $1 \mathrm{~L}$ stoppered glass bottle containing a mixture of $\mathrm{NaOH} /$ monochloroacetic acid ( $\mathrm{Na}$ salt), at a molar ratio of $2 / 1$, in 50/50 ethanol/water using a material to liquor ratio of 10 . The bottle was put in a thermostated shaking water bath for 5 hours at $50^{\circ} \mathrm{C}$. The fibre was then taken out of the bottle, squeezed and the excess alkali was removed by washing with $0.1 \mathrm{~N}$ acetic acid (in 80/20 ethanol/water) until neutralization with phenolphthalein.

\section{Topographical studies of CM cotton fibre - Scanning Electron} Microscopy $^{7}$

The topographical analysis of the CM cotton fibre in comparison with the control (plain) cotton fibre was investigated under scanning electron microscopy. The SEM analysis of the fibres was carried out to identify the difference in the fibre structures after the addition of carboxyl ions. The change in the fibre structure and fibre surface was comparatively investigated in the study. The samples were prepared for SEM using a suitable accelerating voltage $(10 \mathrm{KV})$, vacuum (below $5 \mathrm{~Pa}$ ) and magnification (X 3500). Metal coating was used as the conducting material to analyse the sample.

\section{FTIR analysis of CM cotton fibre ${ }^{8}$}

The alteration in the functional groups of CM cotton fibre due to the addition of carboxyl ions in the Carboxymethylation process was determined chemically using FTIR spectroscopy. The FTIR absorption spectra of the CM cotton and control cotton fibre were recorded in the range of $400-4000 \mathrm{~cm}^{-1}$ by $\mathrm{KBr}$ disc method. FTIR spectra of the samples were determined using Shimadzu FTIR spectrophotometer. All the samples were prepared in $\mathrm{KBr}$ discs with a hydrostatic press at a force of $5.2 \tau \mathrm{cm}-2$ for 3 minutes to reduce the moisture content on the disc surface. Each disc was dried under radiation to remove excess moisture content.

\section{Extraction of herbs ${ }^{9}$}

About 50g of each Gliricidia sepium, Hemigraphis colorata, Ichnocarpus frutescens and Caesalpinia bonduc powdered leaves were extracted with $125 \mathrm{~mL}$ of ethanol separately using Soxhlet extraction apparatus for 3 to 6 hours. The extract was allowed to cool and stored at room temperature in liquid state prior to use. The extract was then used to dye the CM cotton fibre and evaluated for its antibacterial activity.

\section{Dyeing CM fibre using herbal extracts ${ }^{9}$}

The herbal extract was applied on to the carboxymethylated cotton fibre by immersing in a dye bath containing the herbal extract at liquor ratio of $1: 50 \mathrm{ml}$ herbal solution for each gram of the $\mathrm{CM}$ cotton sample at room temperature without heating. Then at $100^{\circ} \mathrm{C}$ sodium chloride was added under closed dyeing system. Finally, the herbal dyes were rinsed in water and dried at $40^{\circ} \mathrm{C}$ for $30 \mathrm{~min}$. The carboxymethylated cotton fibre was dyed similarly under controlled conditions for all the four herbal extracts
(Gliricidia sepium, Hemigraphis colorata, Ichnocarpus frutescens and Caesalpinia bonduc) separately.

\section{Antibacterial activity of $\mathrm{CM}$ fibre ${ }^{10}$}

Antibacterial activity of herbal dyed CM fibres was evaluated against two test organisms, Escherichia coli and Staphylococcus aureus. In this method the pre-measured size $(2.0 \mathrm{~cm}$ dia) of the test materials were tested from each preparation (Gliricidia sepium, Hemigraphis colorata, Ichnocarpus frutescens and Caesalpinia bonduc). Test materials were placed on the surface of Mueller-Hinton agar plate which had previously been seeded with an overnight broth culture of the test organisms and incubated at $37^{\circ} \mathrm{C}$ for 24 to 48 hours. Antibacterial activity was expressed as the diameter of the zone of inhibition or inhibition clear zone (ICZ).

\section{Wicking properties of $\mathrm{CM}$ cotton fibre ${ }^{11}$}

AATCC TM 197, Vertical Wicking of Textiles, is used to measure "the ability of vertically aligned fabric specimens to transport liquid along and/or through them" Wicking rate is a particularly important property that measures a fabric's ability to remove sweat/liquid from contact with the body. The wicking properties were analyzed comparatively for control (plain) cotton and $\mathrm{CM}$ cotton fibres. The wickability of the test fibres was evaluated by time for wetting. During the analysis, the fibre samples were conditioned in a standard atmosphere of $22^{\circ} \mathrm{C}$ under $65 \%$ relative humidity for 24 hours. The pre-measured size $(1.5 \mathrm{~cm} \times 10 \mathrm{~cm})$ of each test mounted on the glass slides was kept at immersed condition inside a reservoir containing artificial blood. The wicking height of the advancing liquid front as a function of time was recorded by visual observation after 5 minutes. Using a standard ruler scale, the colour of artificial blood absorbed on the fibre surface was measured for each sample and the values were recorded.

\section{RESULTS AND DISCUSSION}

Carboxymethylation of cotton fibre (CMC) was carried out in the present research to increase the absorbency and moisture retention properties. The control and carboxymethylated fibres were compared to differentiate these properties with the aid of different testing parameters which are discussed below. Scanning electron microscopy, FTIR and wicking tests were analysed to differentiate the fibre structure, functional groups and absorbency of the respective control and $\mathrm{CMC}$ fibres.

\section{Topographical studies of CM cotton fibre - Scanning Electron Microscopy}

The scanning electron microscopic analysis of the control (plain) cotton fibre and CM cotton fibre was analysed to show the difference in the fibre structures due to addition of carboxyl ions. The change in the structure of fibers surface is comparatively evident. In Fig. 1, the structural morphology of the plain control cotton was presented. From the figure, it was evident that the fibres were twisted and wrinkled with harsh surface which may be caused due to absence of moisture content in the fibre. It was proven that the $\mathrm{CM}$ fibres always have the ability to hold atleast few percentage of moisture content due to the presence of carboxyl ions and its functional groups. This was evident from Fig. 2 attributing the SEM analysis of CM cotton fibre structures. From the figure, it was evident that, the $\mathrm{CM}$ cotton fibres were swollen with few protruding microfibrils. Fiber swelling is due to the sodium hydroxide concentration used during the carboxymethylation reaction. The modified cellulose fibre 
showed few helical ditches orientated along the direction of developed microfibrils.

Table 1. Wicking behaviour of Fibres

\begin{tabular}{|c|c|c|c|c|}
\hline \multirow{2}{*}{$\begin{array}{l}\text { S. } \\
\text { No }\end{array}$} & \multicolumn{2}{|r|}{ Cotton (Control) fibre } & \multicolumn{2}{|r|}{ CM cotton fibre } \\
\hline & Peak & Assignment & Peak & Assignment \\
\hline 1 & $3431.07 \mathrm{~cm}^{-1}$ & simple -OH (hydroxyl) stretching & $3417.30 \mathrm{~cm}^{-1}$ & carboxylic stretching frequency of the $-\mathrm{OH}$ group \\
\hline 2 & $2853.64 \mathrm{~cm}^{-1}$ & $\begin{array}{l}\mathrm{C}-\mathrm{H} \text { (alkane group) stretching } \\
\text { vibration }\end{array}$ & $2852.57 \mathrm{~cm}^{-1}$ & $\mathrm{C}-\mathrm{H}$ (alkane group) stretching vibration \\
\hline 3 & - & - & $1714.25 \mathrm{~cm}^{-1}$ & $\begin{array}{c}\mathrm{C}=\mathrm{O} \text { (carboxylic acid group) carboxylic stretching } \\
\text { vibrations }\end{array}$ \\
\hline 4 & - & - & $1633.87 \mathrm{~cm}^{-1}$ & symmetric stretching of carboxylate anion \\
\hline 5 & $1455.92 \mathrm{~cm}^{-1}$ & C-H (alkane group) bending vibrations & $1455.52 \mathrm{~cm}^{-1}$ & C-H (alkane group) bending vibrations \\
\hline 6 & $1160.59 \mathrm{~cm}^{-1}$ & $\begin{array}{l}\text { C-O-C (ether group) asymmetric } \\
\text { bridge stretching }\end{array}$ & $1157.58 \mathrm{~cm}^{-1}$ & C-O-C (ether group) asymmetric bridge stretching \\
\hline 7 & $1030.00 \mathrm{~cm}^{-1}$ & $\begin{array}{c}\text { carbonyl C-O (carbonyl group) } \\
\text { stretching }\end{array}$ & $1020.66 \mathrm{~cm}^{-1}$ & carbonyl C-O (carbonyl group) stretching \\
\hline 8 & - & - & $748.03 \mathrm{~cm}^{-1}$ & $\mathrm{O}-\mathrm{C}=\mathrm{O}$ carboxylic bending \\
\hline
\end{tabular}

Table 2. Anti-bacterial activity of CM Fibres

\begin{tabular}{|c|c|c|c|}
\hline \multirow{2}{*}{ S. No. } & Herbal dyed cotton fibres & \multicolumn{2}{|c|}{ Zone of Inhibition (in mm) } \\
\cline { 3 - 4 } & & 27 & Staphylococcus aureus \\
\hline 1 & Gliricidia sepium & 26 & 24 \\
\hline 2 & Hemigraphis colorata & 24 & 25 \\
\hline 3 & Ichnocarpus frutescens & 33 & 32 \\
\hline 4 & Caesalpinia bonduc & 24 \\
\hline
\end{tabular}

Table 3. Wicking properties of CM Fibres

\begin{tabular}{|c|c|c|c|}
\hline \multirow{2}{*}{ S. No. } & Herbal dyed cotton fibres & \multicolumn{2}{|c|}{ Wicking height in centimeters } \\
\cline { 3 - 4 } & & 5.1 & Control \\
\hline 1 & Gliricidia sepium & 4.6 & 7.3 \\
\hline 2 & Hemigraphis colorata & 5.2 & 7.5 \\
\hline 3 & Ichnocarpus frutescens & 5.2 & 7.4 \\
\hline 4 & Caesalpinia bonduc & 7.5 \\
\hline
\end{tabular}

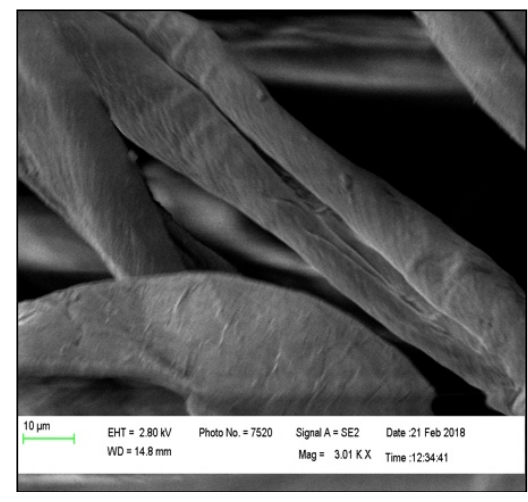

Fig. 1. SEM analysis of (control) cotton fibre

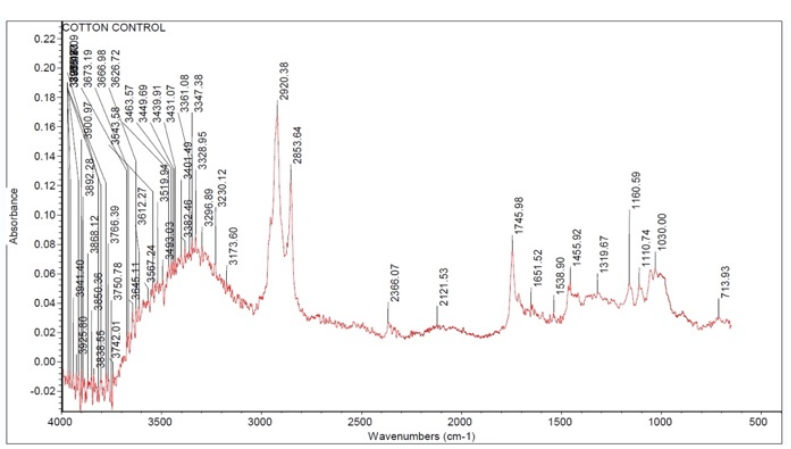

Fig. 3. FTIR spectrum of (control) cotton fibre

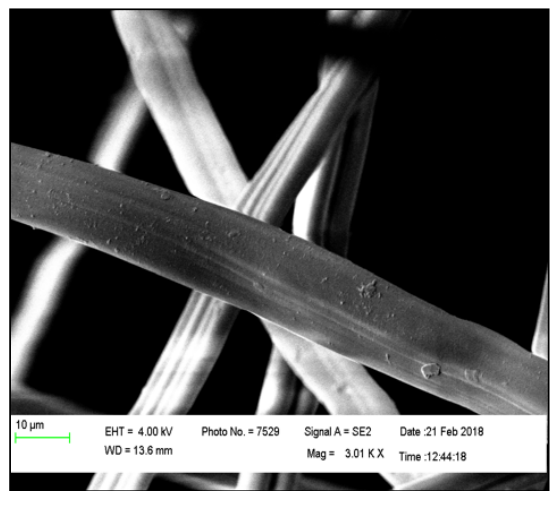

Fig. 2. SEM analysis of $\mathrm{CM}$ cotton fibre

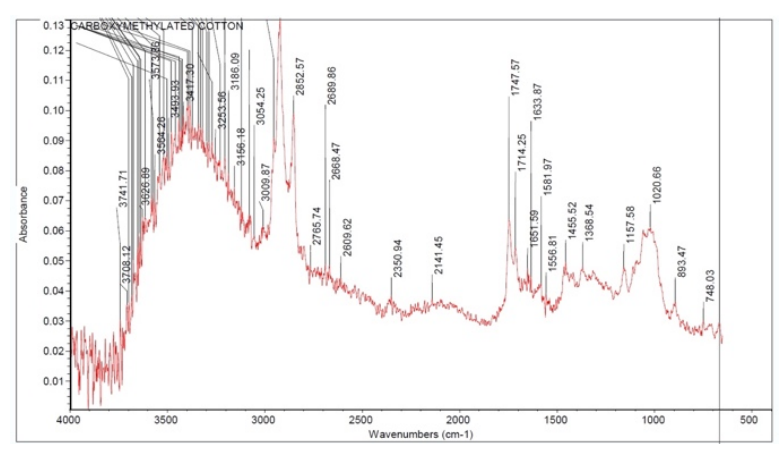

Fig.4 . FTIR spectrum of CM cotton fibre 


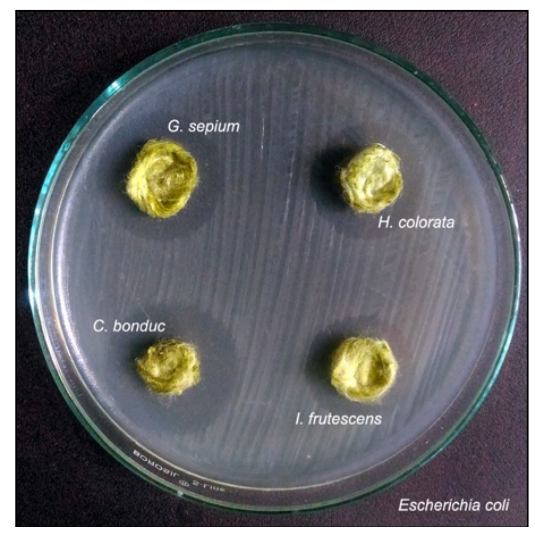

Fig. 5. Antibacterial activity against $E$. coli

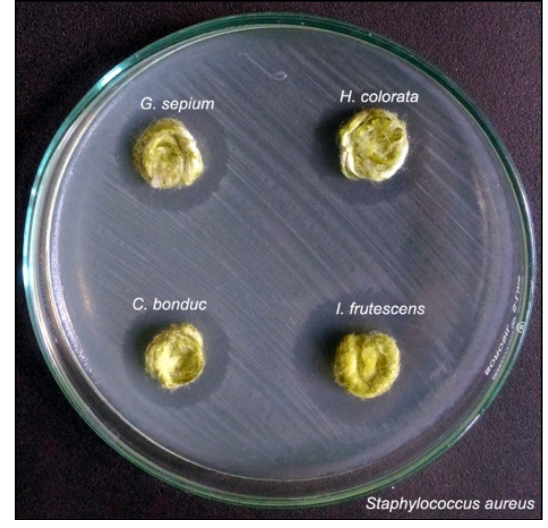

Fig. 6. Antibacterial activity against $S$. aureus

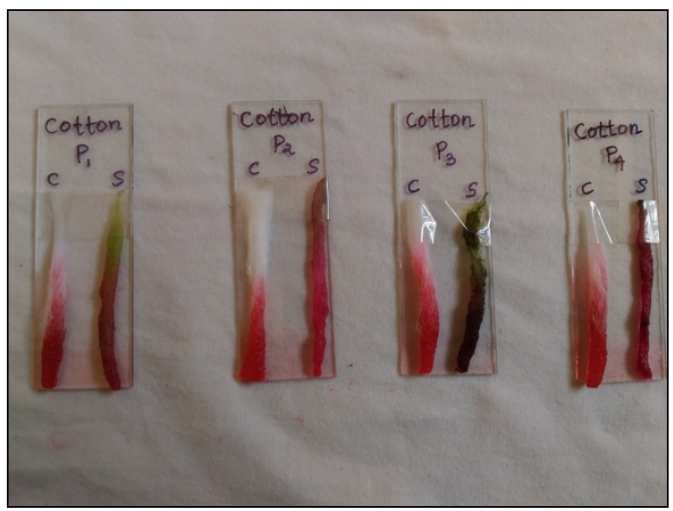

Fig. 7. Wicking properties of control and $\mathrm{CM}$ cotton fibres

\section{FTIR analysis of CM cotton fibre}

FTIR spectrum of the control (plain) cotton fibre and CM cotton fibre was analyzed and presented in Fig. 3 and Fig. 4. The addition of carboxyl ions in the CM cotton attributed the change in their respective functional groups were evident during this study. In Table I, the peaks corresponding to each of its functional groups were presented comparatively for cotton and CM cotton fibre. FTIR spectra of CM cotton fibre showed a broad band at $3417.30 \mathrm{~cm}^{-1}$ due to carboxylic stretching frequency of the $-\mathrm{OH}$ group. Similar peak at $3431.07 \mathrm{~cm}^{-1}$ for the plain cotton attributed for simple $-\mathrm{OH}$ (hydroxyl) stretching. The appearance of broad peaks at $1714.25 \mathrm{~cm}^{-1}$ was attributed to $\mathrm{C}=\mathrm{O}$ (carboxylic acid group) carboxylic stretching vibrations frequency of cellulose in $\mathrm{CM}$ cotton fibre with broad intensities. Interestingly this peak value was found missing in the control cotton fibre indicating the absence of carboxylic stretching vibrations. The presence of a strong band at $1633.87 \mathrm{~cm}^{-1}$ confirms the symmetric stretching of carboxylate anion in CM fibers. This peak was also not evident for the control cotton fibre. These two peaks which were evident only for CM cotton fibre indicated the efficiency of Carboxymethylation process used in the present study. Even though most of the bands are similar for plain cotton and CM cotton fibres, the significant functional groups were found to be attributed specifically to show the modifications in CM cotton fibres. The common peaks attributing to the functional groups of plain cotton and CM cotton fibres are noted separately and discussed below. The band at $2853.64 \mathrm{~cm}^{-1}$ and $2852.57 \mathrm{~cm}^{-1}$ represented the $\mathrm{C}-\mathrm{H}$ (alkane group) stretching vibration for both control and CM cotton fibres. The bands around $1455.92 \mathrm{~cm}^{-1}$ and $1455.52 \mathrm{~cm}^{-1}$ are assigned to $\mathrm{C}-\mathrm{H}$ (alkane group) bending vibrations for both control and $\mathrm{CM}$ cotton fibers respectively. The bands at $1160.59 \mathrm{~cm}^{-1}$ and $1157.58 \mathrm{~cm}^{-1}$ represented the common $\mathrm{C}-\mathrm{O}-\mathrm{C}$ (ether group) asymmetric bridge stretching frequencies of cellulose in cotton and $\mathrm{CM}$ cotton fibres respectively. Peaks at $1030.00 \mathrm{~cm}^{-1}$ and $1020.66 \mathrm{~cm}^{-1}$ were attributed to carbonyl C-O (carbonyl group) stretching frequencies. And the band at $748.03 \mathrm{~cm}^{-1}$ for $\mathrm{CM}$ fibre was assigned to $\mathrm{O}-\mathrm{C}=\mathrm{O}$ carboxylic bending which was not evident for the control fibre. The cotton fibres thus modified with carboxyl ions were monitored for wickability and antibacterial activity. The anionic character of the surface has been proven by cationic herbal dyeing for potential antibacterial activity in the present study which was confirmed in the next section.

\section{Antibacterial activity of CM fibres}

The antibacterial activity of carboxymethylated cotton dyed with four different herbal extracts separately were evaluated against two significant organisms (Escherichia coli and Staphylococcus aureus). During the analysis, all the herbal extract finished CM cotton fibres exhibited excellent inhibitory zones against the test organisms. In Table II the antibacterial activity of the herbal dyed $\mathrm{CM}$ cotton fibres expressing the inhibitory zones measured in millimetre was presented. The same was also illustrated in Fig. 5 and Fig. 6 against Escherichia coli and Staphylococcus aureus respectively.

Two major reasons have been reported for the antibacterial activity of herbal dyed fibres. First reason may be due to the significance of Carboxymethylation process. The carboxymethylated fibre increases the absorbency or wicking properties of any cellulose containing fibres or fabrics. This property was later discussed in the wicking behavioural tests of the CM fibres in comparison with the control (plain) cotton fibres. Due to more herbal dye absorbency, the CM cotton fibres have exhibited more antibacterial activity. In other words, increased concentration of herbal dyes in the CM cotton fibre gets released 
on to the surface of the Nutrient agar media to show more inhibitory zones against the test organisms. Another reason was also recorded during the literature survey in terms of the phytochemical compounds present in the herbal extracts used in the study. The inhibitory zones indicated the antibacterial potential of the herbal compounds that are inherently present. These compounds are the phytochemical compounds named alkaloids, flavonoids, terpenoids, steroids, phenol and polyphenols. The compounds responsible for the antibacterial actions differ from plant to plant based on the type of phytochemical constituents present in the extracts natively.

\section{Wicking properties of $\mathrm{CM}$ cotton fibre}

The wicking properties were analyzed comparatively for control (plain) cotton and CM cotton fibres. As proved the significance of Carboxymethylation process during the SEM and FTIR analysis, the $\mathrm{CM}$ cotton fibre showed excellent wicking (absorbency) and moisture retention properties in the study. The wickability of the test fibres was evaluated by time for wetting. During the analysis, the fibre samples were conditioned in a standard atmosphere of $22^{\circ} \mathrm{C}$ under $65 \%$ relative humidity for 24 hours. The pre-measured size $(1.5 \mathrm{~cm} \times 10 \mathrm{~cm})$ of each test mounted on the glass slides was kept at immersed condition inside a reservoir containing artificial blood. A ruler was placed parallel to the sample strip to enhance the accuracy of the measurement. The wicking height of the advancing liquid front as a function of time was recorded by visual observation after 5 minutes. Using a standard ruler scale, the colour of artificial blood absorbed on the fibre surface was measured for each sample and the values were recorded (Table III). All the CM fibre previously dyed with herbal extracts showed more blood absorbency than the control fibres. The absorbency in terms of time (in minutes) for wetting of the fibres was presented in Fig. 7. It was evident that $\mathrm{CM}$ cotton fibres can easily absorb the artificial blood in the interstices to retain more liquid due to the formation of more absorbent spaces with in. The process enhances more capillary actions by increasing the surface tension of the fibres which causes the blood to flow upward. The stabilized surface tension of the fibre makes the liquid more attracted and retains at higher level.

\section{CONCLUSION}

Based on the significance of Carboxymethylation process, cotton fibre surface was modified to increase the wicking (absorbency) and water retention properties. Topographical analysis of the CM cotton fibre when investigated under SEM showed that the fibres were found swollen with few protruding microfibrils indicating that the fibre was modified with carboxyl ions. FTIR spectra of $\mathrm{CM}$ cotton fibre showed prominent peaks attributing for the functional groups of surface modified fibres. The significant bands at $3417.30 \mathrm{~cm}^{-1}$ and $1714.25 \mathrm{~cm}^{-1}$ found attributed to carboxylic stretching of the $-\mathrm{OH}$ group and $\mathrm{C}=\mathrm{O}$ carboxylic stretching vibrations respectively. Herbal extracts finished CM cotton fibres showed significant antibacterial inhibitory zones ranging from $24 \mathrm{~mm}$ to $33 \mathrm{~mm}$ against Escherichia coli and Staphylococcus aureus. Vertical wicking analysis showed greater absorbency and dye uptake for the carboxymethylated fibres than the normal fibres. Based on the results obtained from SEM, FTIR, wicking and antibacterial activity tests the present research thus illustrated the significance of carboxymethylation process for the development of skin-friendly and eco-friendly products like baby diapers and sanitary napkins.

\section{REFERENCES}

1. Boryo DEA. The effect of microbes on textile material. Intl J Eng Science, 2013; 2 Suppl 8:09-13.

2. Sarika Mishra, Ritu Pandey, Mukesh Kumar Singh. Development of sanitary napkin by flax carding waste as absorbent core with herbal and antimicrobial efficiency. Int $\mathbf{J}$ Sci Environ Tech, 2016; 5 Suppl 2:404 - 411.

3. Sauperl O. Textiles for protection against microorganism. International Advances in Applied Physics and Materials Science Congress and Exhibition, 2016; 1727 Supppl 1:2135.

4. Kalkidan Tadesse, Nalankilli G. Antimicrobial Finishing of Cotton with Extracts of Solanum Incanum Fruit. Int Res J Eng Technol, 2017; 8 Suppl 8:2204-2210.

5. Elayarajah Balasubramanian, Venkatrajah Balasubramanian, Geethu Babu, Devika S, Rajendran R, Moist wound dressing fabrications: Carboxymethylation of antibacterial cotton gauze. Journal of Eng Fiber Fabr, 2013; 8 Suppl 4:78-87.

6. Karolina Boruvkova, Jakub Wiener. Water absorption in carboxymethyl cellulose. AUTEX Res J, 2011; 11 Suppl 4:110-113.

7. Haleem N, Arshad M, Shahid M, Tahir MA. Synthesis of carboxymethyl cellulose from waste of cotton ginning industry. Carbohydrate Polymer, 2014; 26 Suppl 113:249-55.

8. Coates J. Interpretation of Infrared Spectra - A Practical Approach Encyclopedia of Analytical Chemistry. R.A. Meyers (Ed.) O John Wiley \& Sons Ltd, 7 - 15, 2000.

9. Owis AS, An economical dyeing process for dyeing (cotton, polyester and cotton/polyester blend fabrics). J Tex Apparel Technol Manage, 2010; 6 Suppl 4:1-11.

10. EN ISO 20645. Determination of antibacterial activity - Agar diffusion plate test. Technical Committee CEN/TC, 2004: 248.

11. AATCC Test Method 197. Wicking properties of Textile Materials. American Association of Textile Chemist and Colorist, AATCC technical Manual, 2011:159-165.

\section{Cite this article as:}

Shabrin Farhana G and Palaniswamy NK. Carboxymethylation $(\mathrm{cm})$ of natural fibres: Investigating the moisture absorbency and evaluating antimicrobial property of herbal finished $\mathrm{cm}$-fibres. Int. J. Res. Ayurveda Pharm. 2018;9(3):216-220 http://dx.doi.org/10.7897/2277-4343.09396

Disclaimer: IJRAP is solely owned by Moksha Publishing House - A non-profit publishing house, dedicated to publish quality research, while every effort has been taken to verify the accuracy of the content published in our Journal. IJRAP cannot accept any responsibility or liability for the site content and articles published. The views expressed in articles by our contributing authors are not necessarily those of IJRAP editor or editorial board members. 